\title{
«Solitarios refugios de efemérides viejas». Monumentos y ciudades históricas como símbolos nacionales en la prensa gráfica $(1918-1930)^{1}$
}

\author{
Eduardo Hernández Cano \\ New York University
}

RESUMEN: Siguiendo una tradición que se remontaba a mediados del siglo XIX, la prensa gráfica española del primer tercio del XX hizo circular extensamente representaciones de ciudades y monumentos históricos como símbolos de la nación. Partiendo de los trabajos de Benedict Anderson sobre el papel de la prensa en la constitución de imaginarios de comunidades nacionales, y de George L. Mosse sobre la nacionalización de masas a través de los monumentos, este artículo analiza el modo en que estas representaciones formaron una idea cultural de la nación para las clases medias a las que la prensa gráfica estaba destinada.

\section{Palabras Clave: Prensa gráfica; Nacionalismo cultural; Símbolos nacionales; Lectura.}

"Alone Shelters of old ephemeris". Sights and historic cities as national symbols in the ilustrated press (1918-1930)

ABSTRACT: Continuing a tradition that started in the middle XIXth Century, the Spanish illustrated press of the first third of the XXth Century extensively circulated representations of historical cities and monuments. Taking the works of Benedict Anderson on the role of the press in building the imaginaries of national communities, and of George L. Mosse on the nationalization of the masses through monuments as a starting point, this paper analyzes the way in which this representations constructed a cultural idea of the nation for the middle classes to whom the illustrated press was addresed.

\section{KEY WORDS: Illustrated Press; Cultural Nationalism; National Symbols; Reading.}

1 Cita tomada de ZURITA, 1.396 (Madrid, 1918). 


\section{Qui n'a déjà vu l'Escorial dans des rêves illustrés?}

Paul Morand, «Peinture sur soie» $(1920)^{2}$

Acompañando a un discreto dibujo de la puerta del ayuntamiento de Burgos realizado por Agustín Aguirre, la revista La Esfera publicó en 1929 un texto anónimo en el que se podía leer:

Burgos es como un airón en el arte y la historia de España. ¿Cuántas páginas españolas están unidas a la vieja ciudad castellana, arca de virtudes gloriosas y sagrario de reliquias románticas? Todo en Burgos tiene un latido emocionado, bajo la noble serenidad del cielo de Castilla. Plazas, callejas, rincones, guardan palpitaciones de la vieja alma de España, misteriosamente conservada entre las piedras antañonas de la ciudad ${ }^{3}$.

Quien hubiese frecuentado esta revista gráfica apenas repararía, por haberla visto tantas veces antes, en esa unión entre la imagen de un espacio monumental y un texto de marcado nacionalismo en el que, con un cierto lenguaje vagamente literario esmaltado de recurrentes palabras clave - piedras, alma, sagrario, vieja ciudad-, se evocaba la presencia del espíritu de la nación en un lugar histórico. Pero, pese a la proliferación de este tipo de discurso sobre los monumentos históricos en la prensa gráfica, los estudios sobre los símbolos del nacionalismo español apenas le han prestado atención. Esto puede explicarse en gran medida por los propios límites marcados en la historiografía del nacionalismo cultural: un libro como el clásico de Georges L. Mosse dedicado al papel de los monumentos en la nacionalización de masas en Alemania, se centra de manera exclusiva en monumentos de construcción contemporánea y en las prácticas de celebración de la nación allí realizadas, limitándose a apuntar sobre los monumentos históricos que «fueron utilizados como escenario, como un entorno preexistente para el culto a la nación $»^{4}$. El no menos clásico estudio de Benedict Anderson sobre la formación del imaginario nacional destacaba el papel de la prensa en ese proceso, pero analizándola exclusivamente desde la cultura escrita, sin valorar los cambios en las formas de consumo de la idea de nación que la aparición de un tipo de prensa capacitada para la reproducción mecánica de imágenes suponía ${ }^{5}$. Los estudios sobre el nacionalismo cultural español, por su parte, se han movido entre el estudio de las políticas culturales del Estado y el análisis de la producción

2 MORAND, 1920: 19.

3 ANÓNIMO, 784 (Madrid, 1929): 1.

4 MOSSE, 2005: 52. Véase, sin embargo, André Vauchez, «La cathédrale» en NORA, 1997, vol. 3: 3.109-3.140.

5 ANDERSON, 1991: 37-46. 
intelectual seleccionada a partir de un canon básicamente heredado de la historiografía literaria ${ }^{6}$.

Como ya vienen apuntando algunos estudios recientes, es necesario continuar el trabajo realizado en el estudio cultural del nacionalismo ampliándolo a medios difusión masiva como la prensa, tratando de preservar en los análisis la especificidad de los productos culturales, cuyo funcionamiento es siempre más complejo que la sola difusión de ideas políticas ${ }^{7}$. Este trabajo se propone, siguiendo esta línea de estudios sobre el nacionalismo cultural, emprender al mismo tiempo nuevas vías para la comprensión del mismo, estudiando la presencia de los monumentos históricos en la prensa gráfica, tratando de atender a las características específicas de esta como medio y a las prácticas de consumo que propició, y analizando cómo esos símbolos fueron utilizados por ciertos intelectuales para la transmisión de una serie de valores nacionales para construir una idea cultural de la nación española para las clases medias a las que se dirigían.

\section{NACIONALISMO Y PRENSA GRÁFICA: LA TRADICIÓN MONUMENTALISTA}

Lo monumental fue una tradición establecida desde el inicio en el siglo XIX de la prensa ilustrada, como ha estudiado Cecilio Alonso, marcada por una evidente intención nacionalista en la selección de motivos para sus grabados $^{8}$. Esas representaciones de monumentos históricos formaron parte de una naciente cultura visual de amplia difusión gracias a las nuevas técnicas de reproducción de imágenes, verdadera industria de la memoria nacional ${ }^{9}$, en la que destacaron series como los Recuerdos y Bellezas de España (1839-1865), España Artística y Monumental (1842-1850) o España. Sus monumentos y artes, su naturaleza e historia $(1884-1888)^{10}$.

6 BOYD, 1997. FOX, 1998. VARELA, 1999. SÁNCHEZ ILLÁN, 2002. JULIÁ, 2004. MORENO LUZÓN, 2009. SAZ y ARCHILÉS, 2012. Estudios pioneros sobre la formación de la identidad nacional a través de medios de masas son SALAÜN, 1993; 1994. SERRANO, 1999: 131-161. HOLGUÍN, 2002. MENDELSON, 2005. LABANYI, 2005. BERTHIER y SEGUIM, 2007. GARCÍA CARRIÓN, 2007; 2011; 2013. QUIROGA, 2007. De manera más general ver FUSI, 2000: 189-196.

7 MORENO LUZÓN, 2007: 18-19, ha apuntado que «la relevancia de la prensa resulta difícil de exagerar: de las revistas ilustradas que difundían en grabados la iconografía acuñada por la pintura de historia». Una defensa de la especificidad de la cultura en SCHORSKE, 1981: XVIII-XXX.

8 ALONSO, 2001.

9 CHARNON-DEUTSCH, 2008. SEOANE, 1977. La prensa ilustrada en España, 1996. SÁNCHEZ VIGIL, 2008. La idea de «industrias de la memoria» la tomo de ROTH, 2006:161-165.

10 MAESTRE ABAD, 181-182 (Madrid, 1984): 86-93. ARIÑO COLÁS: 2007. GARCÍA 
A partir de los años diez y hasta los años treinta, este tipo de discurso monumentalista proliferó de tal modo en los semanarios gráficos que sólo puede ser explicado por una política editorial en ese sentido ${ }^{11}$. Los dos grupos editoriales en que he centrado mi investigación, Prensa Española, a través de su revista Blanco y Negro, y Prensa Gráfica, a través de Nuevo Mundo y, fundamentalmente, La Esfera, mostraron, pese a sus diferencias políticas, un interés constante en la difusión de la monumentalidad histórica española con intención nacionalista ${ }^{12}$. Como en sus precedentes decimonónicos, la imagen fue clave en este discurso, confiriendo un marcado aire de familia a una extensa variedad de representaciones. Reproducciones de cuadros, apuntes del natural, grabados, marcos decorativos, dibujos y, fundamentalmente, fotografías, ilustrando poemas y artículos monográficos o acompañadas por breves pies, informativos o líricos, presentaron todas las semanas a los lectores imágenes de las ciudades históricas españolas y sus monumentos ${ }^{13}$. Como señalaba José Sánchez Rojas, en los años veinte las ciudades históricas estaban plagadas de fotógrafos ${ }^{14}$, pero ya desde el siglo XIX la fotografía se había convertido en "poderosa aliada de la arquitectura y la arqueología» ${ }^{15}$. Esta larga tradición fotográfica había creado un código visual sencillo pero extremadamente eficaz para la presentación de lo monumental, que oscilaba entre la vista urbana panorámica, el edificio completo y el detalle artístico. No menos reiterativas resultaban las prácticas textuales que acompañaban a esas imágenes, artículos en los que se evocaba la localización geográfica y el paisaje de las ciudades o monumentos, se seguía con el recuerdo históricolegendario de su pasado, para detenerse al fin en la dimensión artística de los monumentos. Con frecuencia aparecía entreverado todo ello de un cierto lirismo evocador, entre el romanticismo histórico y la sensibilidad simbolista. Pero sin duda, el elemento fundamental era un repertorio de fetiches léxicos en los que se unían las referencias a la nación, la historia gloriosa, la raza y

MELERO, 2002. Este modelo pervivió en la prensa gráfica posterior, como muestra la presencia de los grabados de Genaro Pérez de Villa-Amil, ilustrador de España artística y monumental, en La Esfera. TORMES, 607 (Madrid, 1925). ANÓNIMO, 608 (Madrid, 1925); 609 (Madrid, 1925); 610 (Madrid, 1925).

11 La proclamación de la República trajo un significativo desplazamiento del nacionalismo cultural en la prensa gráfica hacia la idea de pueblo, que espero estudiar en el futuro.

12 SÁNCHEZ ROJAS, 842 (Madrid, 1930) dijo de La Esfera «que de tener alguna política concreta y definida es precisamente la de la conservación de nuestro gran patrimonio artístico». Sobre estos grupos editoriales: BUSSY GENEVOIS, 1991. IGLESIAS, 1978. SEOANE Y SAIZ, 1998: 175. CABRERA, 1994. SÁNCHEZ VIGIL, 2008: 140-154. Debo agradecer a Jean-François Botrel que me señalase la importancia de las políticas editoriales.

13 Para un caso concreto ver HERNÁNDEZ CANO, 2009.

14 SÁNCHEZ ROJAS, 766 (Madrid, 1928): 38.

15 LAGO, 1.841 (Madrid, 1929). 
las piedras, repetidos incansablemente artículo tras artículo. Escritura e imágenes se articulaban en una relación de atribución recíproca de significado, confiriendo las ilustraciones materialidad referencial a los textos, que marcaban cómo debían ser sentidas e interpretadas esas imágenes para construir una idea de gloriosa cultura nacional.

Pese al volumen de edición de la prensa gráfica, el elevado precio limitaba su público, quedando esta lejos de lo que entenderíamos en sentido estricto por un medio de masas ${ }^{16}$. Creo por ello que estas políticas editoriales de reafirmación de la cultura nacional fueron específicamente pensadas para públicos de clase media, más permeables tanto a los valores como a las estrategias estéticas con que se presentaba ese discurso nacionalista, es decir, no sólo poseedoras del capital económico, sino también del capital cultural necesario para apreciar sus valores estéticos e históricos ${ }^{17}$.

Esa combinación de la capacidad de reproducción mecánica de imágenes de la prensa gráfica, una cultura nacionalista articulada simultáneamente a través de lo visual y de lo textual y una circulación periódica extensa entre las clases medias, propició la aparición de lo que creo que es un producto cultural específico que denomino superficies monumentales, que dio lugar a una forma concreta de nacionalización cultural cuyo funcionamiento trataré de analizar en adelante.

\section{DE LA PÁGINA AL LECTOR: LAS SUPERFICIES MONUMENTALES Y EL RITUAL NACIONALISTA DOMÉSTICO}

Mi aproximación a la noción de superficie parte de la crítica cultural alemana que, durante los mismos años veinte, llegó a conclusiones teóricas sobre el papel de lo superficial en la cultura de su tiempo tan importantes como las de Sigfried Kracauer al afirmar que:

16 En los años veinte Blanco y Negro llegó a tirar 100.000 ejemplares al precio de una peseta, Nuevo Mundo alcanzó los 80.000 ejemplares y los 50 céntimos de precio; por su parte, La Esfera, a una peseta, descendió desde 1920 de 60.000 a 45.000 ejemplares. MINISTERIO DE TRABAJO Y PRECISIÓN, 1930: 50-51, 56-57, 60-61. MINISTERIO DE INSTRUCCIÓN PÚBLICA Y BELLAS ARTES, 1921: 52-53.

${ }^{17}$ No hay sino comprobar cómo Mundo Gráfico, también editada por el grupo Prensa Gráfica, y que contó con más lectores, declarando entre 120.000-130.000 ejemplares de tirada durante los años veinte, gracias a su precio estable de 30 céntimos, practicó una política editorial completamente diferente, que dedicaba toda la revista a los espectáculos de masas, del fútbol a los toros, pasando por el boxeo y el cine. MINISTERIO DE INSTRUCCIÓN PÚBLICA Y BELLAS ARTES, 1921: 56-57. MINISTERIO DE TRABAJO Y PRECISIÓN, 1930: 60-61. Sobre capital cultural ver BOURDIEU, 2001: 131-164. 
The position an epoch occupies in the historical process can be determined more strikingly from an analysis of its inconspicuous surface-level expressions than from that epoch's judgments about itself. Since these judgments are expressions of the tendencies of a particular era, they do not offer conclusive testimony about its overall constitution. The surface-level expressions, however, by virtue of their unconscious nature, provide unmediated access to the fundamental substance of the state of things ${ }^{18}$.

Lejos de la lectura negativa de Kracauer, su amigo Walter Benjamin, en un artículo publicado un año antes titulado «Nápoles», ensayaba la posibilidad de analizar las imágenes superficiales como un lenguaje que expresa la propia estructura de la sociedad ${ }^{19}$. Creo que con la prensa gráfica nos encontramos de manera ejemplar en ese terreno de la superficie cultural de una época, cuyas características es necesario desentrañar para tratar de comprender el modo en que estas superficies monumentales llegaron de manera mediada a los lectores.

Como bien ha señalado Pierre Bourdieu «una de las ilusiones del lector es la que consiste en olvidar sus propias condiciones sociales de producción, en universalizar inconscientemente las condiciones de posibilidad de su lectura» ${ }^{20}$. Por ello, todo intento de aproximación histórica al consumo de productos culturales debe, para evitar esa ilusión, incluir el análisis de las condiciones históricas de lectura en su momento de producción. Puesto que carecemos de documentación concreta sobre la respuesta de los lectores, trataré en las páginas siguientes de construir teóricamente una hipótesis sobre las condiciones históricas de recepción y consumo de la prensa gráfica, a partir de las percepciones de observadores contemporáneos sobre los efectos de este tipo de cultura visual en sus lectores.

Creo que el encuentro frecuente del lector de esas superficies monumentales en las páginas de las revistas debía propiciar un consumo no focalizado que, tal y como sugería Kracauer, tenía una función comunicativa tan importante como la de un discurso complejo leído con atención ${ }^{21}$. Walter Benjamin consideraba también, hablando del cine, que la percepción distraída era más propicia que la atenta para la penetración de ideas en el consumidor, hipótesis que creo que se puede trasladar a las superficies monumentales ${ }^{22}$. Esta vinculación entre medio, modo de lectura y efecto sobre el lector había sido ya apuntada por otros observadores de la cultura de la época. Luis Bello, en un artículo del primer número de La Esfera señalaba ya que:

\footnotetext{
18 KRACAUER, 1995: 75-86.

19 BUCK-MORSS, 1995: 27.

20 BOURDIEU, 2000a: 116.

21 KRACAUER, 1995: 75.

22 BENJAMIN, 2007: 239-240.
} 
la labor instructiva y educadora de la prensa gráfica, se cumple forzosamente. Ocurre en la revista lo que en el cinematógrafo: que el público adquiere nociones de cosas muchas veces sin la voluntad del peliculista.

Del mismo modo que la imagen cinematográfica condensa en la pantalla más información que la puramente centrada en la acción, la prensa gráfica ofrece toda la realidad al consumidor «atropelladamente, en la más varia y revuelta confusión; se impone y vence las resistencias que pudiera encontrar en un criterio demasiado estrecho» ${ }^{23}$. Era evidente para algunos observadores culturales que el medio de la prensa gráfica y sus estrategias de presentación de la información tenían una cierta efectividad para comunicar ideas y valores más allá de la atención prestada.

Si la noción de superficialidad es fundamental, no menos importante es comprender las propiedades monumentales de estos productos culturales, de las que se podían derivar unos usos equivalentes a los de las arquitecturas físicas. Como señalaba Walter Benjamin, a través de la fotografía "the cathedral leaves is locale to be recieved in the studio of a lover of art" 24 , permitiendo esa presencia ante el lector de los monumentos, bajo la forma de reproducción fotográfica parte de una superficie monumental, el culto a la nación a través del ritual. Pero mientras que para George L. Mosse el culto ritual a la nación en sus monumentos requiere de la participación del pueblo en forma de masas en esos espacios, en el caso de las superficies monumentales el uso ritual de estos lugares no se realiza a través de la presencia física de los participantes, sino del consumo cultural. Este ritual, al que basta encontrarse ante la imagen reproducida consumida en privado, propicia un culto nacional doméstico, individual, dirigido a esas clases medias lectoras de prensa gráfica, sin el pathos populista de las reuniones de masas, por entonces en España más vinculadas a la clase o la religión que a la nación ${ }^{25}$.

Es precisamente el carácter periódico del medio en que estas imágenes se difunden lo que determina esta forma de consumo cultural ritual a través de una repetición similar a la de las prácticas conmemorativas y ceremoniales ${ }^{26}$.

23 BELLO, 1 (Madrid, 1914). Lo monumental llegó también al cine, en producciones como la adaptación de La casa de la Troya, de Alejandro Pérez Lugín, ANÓNIMO, 1619 (Madrid, 1925). ANÓNIMO, 579 (Madrid, 1925a), o en documentales como Castillos de España (1936), de Carlos Veló y Fernando G. Mantilla. Sobre el uso de este, tanto para propaganda republicana como franquista, ver MESEGUER, 2004: 168-169.

24 BENJAMIN, 2007: 221.

25 Sobre el uso de los medios de comunicación de masas como espacio virtual para los rituales en el mundo contemporáneo ver SEGALEN, 2005. Agradezco a Ángel Duarte que me sugiriese el uso del término «doméstico».

${ }^{26}$ Utilizo el término «ritual» para referirme a una práctica periódica en la que una serie de símbolos y acciones preexistentes contribuyen a un proceso de atribución de significado a 
Como bien ha apuntado Marie-Ève Thérenthy la prensa participa:

de la nécessité d'une écriture de la remémoration constante. Cette conclusion pourrait être généralisée à l'ensemble du journal, que la périodicité contraint à la répétition et à la redondance quotidienne pour combler le temps, même limité, qui sépare chaque publication de la suivante. L'expérience de la lecture en continu d'un périodique rend manifeste l'écriture constamment analeptique qui le définit ${ }^{27}$.

La capacidad comunicativa de estas superficies monumentales, aún sin construir un discurso elaborado, se basa en su continuidad, en la familiaridad que los lectores adquirían con esa literatura y esas imágenes monumentales nacionalistas, por las que podía pasar sin detenerse en una lectura atenta, pues todas resultaban similares y reincidían en la misma articulación, estética y de valores, actualizados en cada nuevo encuentro.

En definitiva, creo que por todas estas características podemos considerar las superficies monumentales parte ese "complex of beliefs, assumptions, habits, representations and practices in a banally mundane way" señalado por Michael Billig, mediante los cuales "the citizenry are daily reminded of their national place in a world of nations. However, this reminding is so familiar, so continual, that it is not consciously registered as reminding" 28 . No comparto, sin embargo, con Billig la inclinación a denominar ese nacionalismo como banal, por ser término equívoco. Creo más ajustado considerar este nacionalismo, siguiendo la definición de Benedict Anderson, "as if it belongued with 'kinship' and 'religion', rather than with 'liberalism' or 'fascism"' 29 , es decir, un elemento de cultura que contribuye de manera global a la atribución de significado a la realidad, llegando a configurar lo que podríamos denominar un habitus nacional ${ }^{30}$.

Gracias a la prensa gráfica y a través de las superficies monumentales el consumidor de clase media recorría de manera regular los mismos temas, imágenes, mitos y valores nacionales. Como señalaba un anónimo redactor:

no por divulgadas, no por repetida su belleza en las páginas de la revista o del libro, dejan de ser las ciudades españolas fontana inagotable de emoción, riquezas de arte que debieran ser familiares a la retina de todos.

Preguntándose después cuántas veces se habrían «reproducido, elogiado y comentado las bellezas de aquellas tres ciudades», justifica esa reiteración

partir de una serie de ideas compartidas por una comunidad, dando forma a una identidad a través del relato.

27 THÉRENTY, 2007: 53.

28 BILLIG, 1995: 6, 8.

29 ANDERSON, 1991: 5.

30 BOURDIEU, 1999: 47,131. 
afirmando que «es preciso que todo español esté saturado de esas bellezas, las ame y las conozca», adquiriendo una total familiaridad con ellas ${ }^{31}$. Poco podemos saber sobre cómo los lectores de aquellas revistas recibieron estas imágenes, pero es evidente que para los observadores de la época esa repetición sistemática de superficies monumentales tenía unos efectos adecuados a sus metas: difundir una idea de nación encarnada en los lugares históricos.

\section{El Pasado como esencia de la nación: la cultura del historicismo NACIONALISTA}

La difusión de estas superficies monumentales participaba de la nueva fase de redefinición étnica e historicista de la cultura nacional que José María Jover llamó «nacionalismo retrospectivo», iniciada durante el periodo isabelino y que rompía con la configuración cívica del nacionalismo liberal de la primera mitad del XIX ${ }^{32}$. Esta obsesión por la nación en su historia fue canalizada no sólo a través de la historiografía, cuya labor fue fundamental, sino también a través de una cultura de la historia cuya continuidad se extiende desde el moderantismo decimonónico hasta bien entrado el siglo $\mathrm{XX}^{33}$.

La historia adquiere en este discurso un carácter mítico-legendario, al que no era ajena la propia práctica historiográfica, pero que aquí tiene sus referentes fundamentales en la literatura historicista del siglo XIX, desde los romances históricos del Duque de Rivas o Zorrilla a las leyendas de Bécquer ${ }^{34}$, pasando por la novela y el teatro históricos, que el revitalizado nacionalismo etnocultural de principios del siglo XX volvería a practicar ${ }^{35}$. La indudable importancia de la historiografía en la configuración de la cultura nacional, muy estudiada ${ }^{36}$, no debe hacernos olvidar esta cultura historicista vulgarizadora que sin duda tuvo, a través del espectáculo, la pintura, la prensa, la literatura e incluso los muebles, una circulación mucho más extensa que el discurso historiográfico. Es necesario analizar el papel de esta cultura historicista en la articulación de valores nacionales, muy en especial, en relación con esa

31 ANÓNIMO, 600 (Madrid, 1925).

32 JOVER, 1991: 165. Sobre nacionalismo étnico y cívico aplicado al caso español ver MURO Y QUIROGA, 5/1 (Londres, 2005).

33 Para el aspecto literario de esa continuidad ver ALONSO, 2010, y MAINER, 2010. Amplío aquí el argumento apuntado en HERNÁNDEZ CANO, 2009: 384-385.

34 BENÍTEZ, 1971: 57-58.

35 ÁlVAREZ JUNCO, 2003: 19. ARA TORRALBA, 1996. RUBIO JIMÉNEZ, 1993.

36 JOVER, 1991. MORENO ALONSO, 1979. CIRUJANO MARÍN, ELORRIAGA PLANES Y PÉREZ GARZÓN, 1985. ÁLVAREZ JUNCO, 2001. WULFF, 2003. PELLISTRANDI, 2004. MORALES MOYA Y ESTEBAN DE VEGA, 2005. PEIRÓ, 2006. FLITTER, 2006. 
mística del espacio histórico nacional que la prensa gráfica difundió masivamente durante el primer tercio del siglo veinte, leyendo las ciudades desde la tradición del romancero y su actualización decimonónica, desde la evocación simbolista de la historia de un Azorín o desde la narrativa histórica de un Enrique Larreta o Ricardo León ${ }^{37}$. Cristóbal de Castro sintetizaba bien los referentes intelectuales de muchos de sus compañeros, en cuyos trabajos «la Historia, la Leyenda y la Poesía - esas tres reinas magas del Oriente espiritualvienen en sus camellos épicos o líricos, a la adoración de la Raza» ${ }^{38}$.

Más allá de la influencia de esos filtros literarios, es necesario señalar que para esta estética historicista los espacios monumentales no constituyen tanto metafóricos lugares de la memoria como presencias materiales del pasado, siendo la propia materialidad de esas ciudades y edificios fundamental para entender el sentido que se daba a este discurso. Los monumentos, las ciudades históricas, no son relatos históricos que se puedan constituir de manera teleológica, selectiva, porque no son textos ni relatos, aunque sean objeto de relatos y textos. Las ciudades, sus edificios supervivientes y los monumentos, urbanos o no, son presencias efectivas, en las que «la historia ha dejado más perdurables huellas. Cada piedra, cada casa, cada calle es una bella evocación histórica», porque, como señala Eelco Rumia "in presence, the past is present in the here and now"39. El espacio queda impregnado de este modo del recuerdo de su historia, un "espíritu del pasado» que conlleva unos valores que se presentan, por ser nacionales, como anteriores y por encima de lo político ${ }^{40}$.

\section{PIEDRAS Y RAZA: SUPERFICIES MONUMENTALES Y VALORES NACIONALES}

Los espacios y monumentos históricos se convertían así en lo que tantas veces se llamó «relicarios de la raza», verdaderas ontopologías, lugares en los

37 ALONSO, 430 (Madrid, 1922). SÁNCHEZ ROJAS, 1.792 (Madrid, 1928). Para Azorín PITA, 1.485 (Madrid, 1919). LOZANO, 753 (Madrid, 1928). Sobre Larreta LÁMPEREZ Y ROMEA, 1.455 (Madrid, 1919). Ricardo León aparece en MONTERO ALONSO, 446 (Madrid, 1922); 606 (Madrid, 1925); FRANCÉS, 807 (Madrid, 1929). ANÓNIMO, 600 (Madrid, 1925) recuerda la tradición legendaria de Zorrilla y el duque de Rivas.

38 CASTRO, 876 (Madrid, 1930): 20. El elemento literario tenía para él una función dinamizadora básica, al «dar carne y sangre a la Leyenda y aliento y movimiento a la Historia», CASTRO, 876 (Madrid, 1930): 21.

39 RUNIA, 45 (Middletown, 2006): 316. ANÓNIMO, 579 (Madrid, 1925c).

40 PITA, 1.465, (Madrid, 1919); 1.473 (Madrid, 1919); 1.477 (Madrid, 1919). LÁMPEREZ Y ROMEA, 1.455 (Madrid, 1919). HOYOS, 473 (Madrid, 1923). DOTOR, 613 (Madrid, 1925). MONTERO ALONSO, 446 (Madrid, 1922). ANÓNIMO, 783 (Madrid, 1929). Sobre el cambio de valores en la interpretación de las ruinas históricas y su reformulación nacionalista ver FRITZSCHE, 2004: 103 y ss. 
que el ser, en este caso nacional, se encarnaba, se hacía esencia ${ }^{41}$. La materialidad del urbanismo y la arquitectura cristalizaban el espíritu de un momento de la historia capaz de definir de manera esencial la identidad nacional:

Castillos de España... No son quimeras, no; ni alegorías ficticias... Son reductos, cálices, orlas invioladas, en las que se guarda, con lo mejor de nuestra historia, lo más selecto de nuestro espíritu, lo más recio y perenne del alma de nuestra raza... ${ }^{42}$.

Vicente Lampérez apuntaba muy claramente la relación que los monumentos tenían con un momento concreto del pasado histórico y su capacidad para condensar cierto espíritu de la nación al recordar el origen de la catedral de Salamanca y cómo en los momentos gloriosos de la historia, «la Arquitectura, arte reflectora siempre del estado social, plasmó el ambiente nacional en una serie de magnos edificios» ${ }^{43}$. Más claro aún era el poeta Marciano Zurita, sintetizando una idea común a todos estos textos, al decir que:

el alma de la raza se concreta en unas cuantas moles de granito, contra las que inútilmente luchará el tiempo, demoledor de cumbres y de glorias. España vive en ellas, extática y solemne, desafiando a los siglos y a las nubes ${ }^{44}$.

La nación se encarnaba así en unos monumentos que permitían a los ciudadanos contemporáneos encontrarse con la esencia de la raza, localizada en la historia y depositada por ella en las piedras viejas de esos lugares ${ }^{45}$.

Los monumentos son valiosos para el discurso nacionalista no sólo en por su aspecto histórico, sino también por difundir valores constituidos en la historia ${ }^{46}$. Los lugares monumentales, «airón y orgullo de España, relicarios de gloriosas tradiciones, templos de fe y de amor, ejemplos de heroísmo, de tenacidad y de mérito», se convierten así en referentes morales ${ }^{47}$. ¿Pero qué valores nacionales articulaban esas representaciones sistemáticas de ciuda-

41 Tomo el concepto de ontopología de DERRIDA, 2006: 102-103.

42 ANÓNIMO, 783 (Madrid, 1929).

43 LÁMPEREZ Y ROMEA, 1.447 (Madrid, 1919).

44 ZURITA, 1.934 (Madrid, 1928).

45 Estas ideas estaban tan extendidas que GÓMEZ DE LA SERNA, 448 (Madrid, 1922), podía afirmar: «Hay que ir de vez en cuando a Segovia, porque en ella se ve con más lógica y con más unidad que en Toledo el alma española, sin la brevedad que ese espectáculo tiene en Ávila y sin la tétrica, solitaria y desesperada visión del Escorial». Sobre la idea de raza en el nacionalismo español ver MARCILHACY, 2010.

46 Para LÁMPEREZ Y ROMEA, 1.483 (Madrid, 1919), la catedral de Toledo «en el aspecto histórico, ancho campo ofrece para el estudio, no sólo en el relato de los hechos de su fundación, sino en la filosofía que de ellos se desprende».

47 ANÓNIMO, 783 (Madrid, 1929). 
des históricas como Burgos, Toledo, Granada, Salamanca o Santiago de Compostela?

La marca moral fundamental había sido dejada en castillos y catedrales, pero también en los espacios urbanos, por la religión y la milicia, con frecuencia vinculada a la nobleza ${ }^{48}$. La idea del alma española se carga así de valores conservadores, como queda claro con sólo ojear la serie «Del noble solar hispano», que Marciano Zurita publicó en Blanco y Negro a lo largo de 1918, donde encontrarnos de manera recurrente esta clase de referencias morales a la nobleza y la Iglesia ${ }^{49}$. Pocos artículos son tan explícitos en este sentido como el dedicado por Ángel M. ${ }^{\mathrm{a}}$ Castell a Burgos, ciudad que:

armoniza lo espiritual y lo terreno, lo piadoso y lo militar, lo oficial y lo privado, Burgos sabe dar forma práctica a las sabias máximas «A Dios lo que es de Dios y al César lo que es del César» $\mathrm{y}$ «A Dios rogando y con el mazo dando» ${ }^{50}$.

También en otras ciudades, como Santillana del Mar, Santiago de Compostela o Ávila «lo guerrero se funde con lo místico. Los escudos nobiliarios están cerca de las portadas de los conventos $\rangle^{51}$. Este pasado clerical e hidalgo se convertía así en el centro de la interpretación de estos espacios nacionales; como señalaba Julio Hoyos «la iglesia y el cuartel son las dos sólidas columnas sobre las que descansan el poder y la influencia de estas viejas ciudades de Castilla» ${ }^{52}$. Como resultado de esa proximidad, con frecuencia edificios religiosos y militares se vuelven indistinguibles, pareciendo simultáneamente iglesias y castillos ${ }^{53}$. Junto a estos valores aparece también la mitificación de la hidalguía castellana como identidad civil, encarnada sobre todo en la imagen recurrente de los edificios blasonados ${ }^{54}$.

Todos estos valores sociales heredados de la historia acaban por tener además una localización geográfica definida, que permite unir la tradición hidalga de casonas y palacios con los castillos de la nobleza militar, los mo-

48 El papel de la iglesia y la monarquía en la creación de lugares de memoria ha sido señalada por André Chastel, «La notion de patrimoine», en NORA, 1997 vol. 1: 1.434.

49 HERNÁNDEZ CANO, 2009.

50 CASTELL, 1.463 (Madrid, 1919).

51 MONTERO ALONSO, 606 (Madrid, 1925). LOZANO, 753 (Madrid, 1928). SÁNCHEZ ROJAS, 845 (Madrid, 1930).

52 HOYOS, 473 (Madrid, 1923).

53 LÁMPEREZ Y ROMEA, 1.455 (Madrid, 1919). VELASCO ZAZO, 656 (Madrid, 1926): 30-32. SÁNCHEZ ROJAS, 1.792 (Madrid, 1928).

54 LÁMPEREZ Y ROMEA, 1.447 (Madrid, 1919), dice de las catedrales de Salamanca: «Pequeña, severa y fuerte aquélla, cuanto enorme, elegante y ligera esta; íntimamente unidas por el flanco, semejan la pareja de dos nobles caballeros». OLMEDILLA, 816 (Madrid, 1929): 32-33. PITA, 1.452 (Madrid, 1919). ROMÁN MARTÍNEZ, 544 (Madrid, 1924). RAMÍREZ ÁNGEL, 559 (Madrid, 1924). LÓPEZ MARTÍN, 851 (Madrid, 1930). 
nasterios y las catedrales. Historia, valores, monumentos históricos y, con ellos, la identidad nacional, se encuentran enraizados en un territorio geográfico, el de la Castilla histórica ${ }^{55}$, que abarca hasta el Cantábrico. Sólo Galicia muy ocasionalmente y ciudades andaluzas como Córdoba o Granada compiten con ella ${ }^{56}$.

Los castillos muestran en sus piedras «pura esencia del alma de Castilla» y las ciudades históricas cristalizan el momento en que «Castilla irradiaba su carácter sobre las Españas» ${ }^{57}$. La nación aparece así encarnada en un canon de ciudades históricas, que incluye las provincias en las que se encuentran ${ }^{58}$. Segovia, León, Toledo, Ávila, Santiago de Compostela o Santillana del Mar aparecen unidas tanto en una ruta histórico artística como en una hermandad espiritual $^{59}$, convertidas en modelo de valores históricos y espirituales para otras ciudades, como las andaluzas o las canarias ${ }^{60}$.

Pero al mismo tiempo, y precisamente por la presencia constante de la historia en ella, Castilla es la encarnación de la distancia entre el ayer y el hoy, en la que se sintetizada el pathos nacionalista del fracaso histórico de España ${ }^{61}$. La localización de la esencia de la nación en el pasado da un tono jeremiaco al monumentalismo nacionalista, tanto en términos político-identitarios como en lo referente al patrimonio artístico de la nación ${ }^{62}$. En algunas ocasiones, ese nacionalismo jeremiaco se tinta del tópico simbolista de la ciudad muerta, cuya resonancia en estos textos indica una vez más que la sentimentalidad intelectual con la que se mira al pasado está determinada por filtros lite$\operatorname{rarios}^{63}$. No sorprende, por tanto, que la queja jeremiaca sea motivo de elabo-

55 GARCÍA SAINZ DE BARANDA, 814 (Madrid, 1929). Sobre Castilla en el nacionalismo español ver MORALES MOYA y ESTEBAN VEGA, 2005: 16-17, y VARELA, 1999: 145-176.

56 SÁNCHEZ ROJAS, 4 (Madrid, 1914). LAGO, 760 (Madrid, 1928).

57 ALONSO, 430 (Madrid, 1922). HOYOS, 473 (Madrid, 1923). MONTERO ALONSO, 562 (Madrid, 1924): «las viejas ciudades [...] hoy son como relicarios en que se guardan los más bellos recuerdos de la raza castellana».

58 Para Ávila, ANÓNIMO, 579 (Madrid, 1925c). Para Segovia, DOTOR, 743 (Madrid, 1928). Para Salamanca, CONTRERAS Y CAMARGO, 768, (Madrid, 1928): 10-11. Sobre Cantabria ANÓNIMO, 579 (Madrid, 1925b).

59 MONTERO ALONSO, 446 (Madrid, 1922); 606 (Madrid, 1925). ANÓNIMO, 579 (Madrid, 1925b). ANÓNIMO, 600 (Madrid, 1925). LOZANO, 753 (Madrid, 1928).

60 Sobre Andalucía ver BELLO, 767 (Madrid, 1928), y SÁNCHEZ ROJAS, 1.833 (Madrid, 1929). Sobre Canarias ver GUERRA, 1.490 (Madrid, 1919), y ALEJANDRO, 1.886 (Madrid, 1930).

61 ANÓNIMO, 579 (Madrid, 1925c).

62 ALONSO, 430 (Madrid, 1922).

63 Sobre ciudades muertas ver HINTERHÄUSER, 1998. MONTERO ALONSO, 446 (Madrid, 1922). VALERO MARTÍN, 629 (Madrid, 1926). SARTHOU CARRERES, 1.471 (Madrid, 1919). 
ración lírica, como en el caso de Fernando López Martín, que en un poema significativamente titulado «Piedras», presenta esa imagen metonímica recurrente en los textos de los espacios monumentales «cual lámparas votivas de una gloria formidable / que pasó», como hidalgos arruinados, extendiendo la decadencia material a lo económico, pero también implícitamente a lo moral $^{64}$. Juan Antonio Cavestany, miembro de la Real Academia Española, elaboró en dos sonetos dedicados a Santiago de Compostela esa oposición entre el pasado glorioso, las «nobles vejeces» y «la leyenda escrita en piedra», que la ciudad hidalga evoca, encarnada fundamentalmente por la figura al mismo tiempo guerrera y religiosa de Santiago, y la simple realidad presente de una ciudad que es «la sombra de las glorias del pasado» ${ }^{65}$. Las mismas jeremiadas aparecen en historiadores del arte como Ángel Dotor, para el que lugares como el castillo de Coca, poblado de «muertos vestigios y recuerdos de su pasado», sólo conservados en la historia semilegendaria ${ }^{66}$, o como la villa de Cuellar, «dormida hoy con el recuerdo nostálgico de su pasado esplendor», son el índice de un pasado nacional glorioso sólo presente ya en los monumentos históricos ${ }^{67}$.

Este desplazamiento de la nación al pasado, que sitúa el espíritu de la raza en los monumentos, en las piedras, muestra claramente que en este discurso la nación no se esencializa en un sujeto político. Frente al nacionalismo cívico progresista decimonónico, que construye su legitimidad sobre la idea de la nación como conjunto de ciudadanos que comparten derechos comunes, la evolución del nacionalismo a lo largo del siglo XIX, y sobre todo durante los gobiernos moderados y la Restauración canovista, contribuyó a edificar un Estado nacional elitista en el que la ciudadanía venía definida por la propiedad, mientras que la esencia de la nación se trasladaba a la historia, la cultura y la lengua, dando forma a esa cultura historicista de la que las superficies monumentales forman parte, apartando de la nación a una sociedad civil cada vez más conflictiva y peligrosa para los intereses de esas clases propietarias, los verdaderos ciudadanos del Estado liberal. La esencia de la nación, petrificada en su historia, quedaba así a salvo de su conflictivo presente y de su incierto futuro ${ }^{68}$.

64 LÓPEZ MARTÍN, 669 (Madrid, 1926).

65 CAVESTANY, 1.413 (Madrid, 1918).

66 DOTOR, 591 (Madrid, 1925).

67 DOTOR, 610 (Madrid, 1925).

${ }^{68}$ Ver las entradas «Pueblo» por Juan Francisco Fuentes y «Nación» por José María Portillo Valdés en FERNÁNDEZ SEBASTIÁN Y FUENTES, 2002: 586-593, 468-476. Mi visión de las relaciones entre Estado, propiedad y nacionalismo debe mucho a mis conversaciones con Alejandro Alonso. 


\section{INTELECTUALES Y ESPÍRITUS: LA CREACIÓN DE UNA SENSIBILIDAD NACIO- NAL PARA LAS CLASES MEDIAS}

Los textos que nos proporcionan las claves de lectura de las superficies monumentales fueron suministrados por publicistas, en el sentido más amplio de la palabra, como José Sánchez Rojas, José Montero Alonso, Luis Bello o Santiago Camarasa, nombres habituales todos ellos en el periodismo de la época, o por eruditos e historiadores del arte profesionales como Ángel Dotor, Vicente Lampérez, o Carlos Sarthou Carreres. Existen sin embargo en todos ellos dos rasgos comunes; primero, un pathos historicista que lleva a vivir la relación con el pasado en forma de emoción, y segundo, un sistema de referencias literarias que articula textualmente esa emotividad, en muchos casos, como hemos visto, refiriéndose explícitamente a los modelos literarios que les permiten pensar los espacios monumentales ${ }^{69}$. Me interesa ahora centrarme sólo en un aspecto concreto del papel mediador de los intelectuales en este discurso nacionalista: la creación de un sentimiento de la nación como estrategia de nacionalización. Trataré de apuntar tentativamente algunos datos para una posible historia de las formas de sensibilización, fundamental como parte del proceso de nacionalización cultural, en un intento de objetivar lo subjetivo a través de la interpretación de unas estrategias literarias conscientes que trataban de hacer además de decir.

Para estos intelectuales, como señalaba Juan López Núñez, la historia no era una forma de conocimiento, sino una forma de sensibilidad:

en la inconsciencia de la vida contemporánea es muy frecuente ver detractores del pasado para quienes la Historia no existe, porque no existe para ellos ningún sentimiento ni ninguna idealidad ${ }^{70}$.

Y frente a quienes ignoraban la historia se situaban ellos, capaces de reconocer en ese pasado la esencia de la nación y de difundir esa idea a través de una serie de operaciones algo más compleja que la simple transmisión de información. Los intelectuales se constituían de ese modo a sí mismos como pieza clave en el proceso de creación de la cultura nacional. Un curioso artículo sobre la ciudad histórica francesa de Carcasona planteaba en 1928 claramente el problema, aplicándolo al caso español. Según este, salvo muy contadas excepciones, «los monumentos españoles sólo han herido la sensibilidad erudita y seca de los arqueólogos», y sin la labor de los poetas no es posible que se desarrolle el amor a las «piedras viejas del alma nacional». La estrategia para cambiar esa situación era muy clara:

${ }^{69}$ La idea de pathos historicista en SCHORSKE, 1981: 66.

70 LÓPEZ NÚÑEZ, 1.710 (Madrid, 1926). 
ni las guías ni los manuales lograrán otra cosa que llenar la memoria de datos eruditos: para que esos hechos del vivir añoso tengan la repercusión exaltadora del alma nacional, la que engarzando el espíritu de la patria chica con todas sus esencias, en el espíritu de la patria grande, soñada más grande aún, pueda engendrar emoción, hace falta la exaltación lírica de los poetas que saben arrancar su secreto a cada piedra vetusta y hacer resurgir en su imaginación primero, y en sus versos después, la vida intensa, cálida, generadora, que pasó y que vuelve en sus ensueños y en sus relatos legendarios.

Era necesario, por tanto, que los poetas devolviesen a «nuestra historia la poesía que daba su perfume heroico al alma nacional» $»^{71}$. El artículo llegaba algo tarde, pues como hemos venido viendo, si no los grandes poetas, al menos sí un nutrido grupo de intelectuales estaban tratando de dotar de poesía al monumentalismo nacional. Tanto los historiadores del arte como los literatos profesionales -Vicente Lampérez, Carlos Sarthou José Montero Alonso, José Sánchez Rojas - practicaron una prosa de densa elaboración literaria, si bien reiterativa en sus tópicos, como cabía esperar por tratarse de superficies monumentales ${ }^{72}$. Pero el elemento literario tenía una importancia que va mucho más allá del estilo, escasamente original, como decimos, común a la mayor parte de estos textos monumentalistas. Mayor importancia tienen las estrategias que los intelectuales utilizan para la sensibilización de sus lectores en lo nacional, para cuya mejor comprensión contamos con un sugerente artículo de Luis Bello, en el que se pregunta precisamente, por qué el espectador siente ante los monumentos:

¿Qué especie de emoción despiertan en nosotros, españoles, castellanos —es decir, dos veces españoles - , las piedras doradas de Salamanca, el hosco y macizo muro de Ávila y estas torres, estas callejas de Segovia, por donde nadie asoma que pueda recordarnos el momento presente? Quizá el sosiego y el indefinible bienestar que nos templa el alma viene de una misteriosa concordancia entre el espíritu de las piedras y el nuestro. Es como una vuelta a la naturaleza ciudadana o - para no hablar en cifra- como un retorno al viejo solar ${ }^{73}$.

La respuesta de Bello, llena de tópicos ya vistos, no está exenta de complejidad por el modo en que une lo distante. En primer lugar, desplaza a sus lectores consigo mismo, cronista de viajes nacionales, hasta unos lugares con los que no necesariamente debían tener familiaridad alguna: las ciudades históricas castellanas. Los lectores se ven de repente transportados a través de la

71 D. T., 761 (Madrid, 1928).

72 LAMPÉREZ Y ROMEA, 1.447 (Madrid, 1919); 1.455 (Madrid, 1919). SARTHOU CARRERES, 816 (Madrid, 1929). MONTERO ALONSO, 446 (Madrid, 1922); 623 (Madrid, 1925).

73 BELLO, 537 (Madrid, 1924). 
escritura a ese espacio provincial en el que quedan reunidos de inmediato, en un giro intersubjetivo establecido por ese plural equívoco, con el propio escritor. El lector es llamado a sentir, como español, junto al escritor, que identifica una reacción estética y emocional ante un espacio que previamente ha identificado como nacional. En su labor de mediación cultural entre el lector y la ciudad histórica, el escritor se presenta como órgano sensible, poseedor de la historia y la idea de nación, y llama al lector a ponerse al mismo nivel, a identificarse en la unidad y a reconocerse en lo que es presentado como su origen mismo. Escritor y lector se encuentran en lo que comparten, la raza, que supone además una forma de propiedad compartida de los espacios históricos con los que se identifica: «¿por qué sentimos una alegría tan íntima? ¿Es que consideramos todo lo que allí vemos, desde el cielo hasta los guijos del empedrado, como cosas genuinas, que nos pertenecen por haberlas creado nuestra raza?» ${ }^{74}$. En apenas unas líneas de un artículo de tantos, el escritor ha llevado al lector a través del espacio hasta los lugares históricos, le ha informado de que son propiedad suya por derecho de raza, insistiendo, por último, que su identidad como español debe tener una vibración sensible ante todos esos elementos: historia, región, raza, propiedad. La intención del escritor es, de manera evidente, socializar su propia respuesta emocional, acogiendo en su experiencia al lector a través de la escritura, apelando a la común españolidad y a la raza. Bello, como intelectual, reproduce en su escritura su propia relación con la realidad representada, fundada sobre cierto conocimiento e interpretación de la historia de España, y la legitima a través de una sensibilidad, indudablemente cargada de valores, que debe ser forzosamente compartida por esos ciudadanos naturales. No hay, sin embargo, nada de natural en reconocer que existen espíritus capaces de encarnarse en las piedras, uniendo así presente y pasado esencial, o en afirmar en consecuencia que «la emoción que sentimos viene, en efecto, del carácter genuino y único que nos revela cada piedra de la vieja ciudad castellana $\rangle^{75}$. Los intelectuales, en definitiva, habitan con el fantasma de un espíritu nacional esos lugares históricos y tratan de llevarlos al interior de sus lectores, lo que requiere por parte de estos una creencia previa en los espiritus (nacionales) y en la capacidad de la realidad para representarlos simbólicamente a través de su propia materialidad o del reconocimiento en el momento de lectura de esas presencias ${ }^{76}$. En definitiva, lo que se está buscando es un lector capaz de reconocer la práctica de una escritura espiritual intersubjetiva, que desde principios del siglo XX reci-

74 BELLO, 537 (Madrid, 1924).

75 BELLO, 537 (Madrid, 1924).

76 MONTERO ALONSO, 606 (Madrid, 1925): «Santillana del Mar tiene una fuerte fraternidad espiritual con Compostela y con Ávila. En ellas tres el pasado surge en cada piedra, en cada minuto, como un fantasmas que adquiriese milagrosa vida real». 
bía el nombre de simbolismo, y que ahora es actualizada con una clara función nacionalizadora. Lo que aporta el simbolismo no es la emoción en sí misma, sino aquello que la hace posible en el escritor y transferible al lector, a través de unos principios estéticos que el primero parece creer que son activos y capaces de influir en el segundo, formando ambos parte implícitamente de una misma comunidad interpretativa estético-intelectual, además de nacional.

En gran medida, lo que los intelectuales están haciendo en estos textos es reproducir su propia mirada escolástica sobre la realidad, suponiendo a sus lectores la misma capacidad espiritual, esto es, interpretativa, que a sí mismos. Los lectores quedarían así insertos dentro de un sistema de producción / reproducción intelectual de ciertas categorías de clasificación de los objetos del mundo que deben provocar la sentimentalidad y el reconocimiento estéti$\cos$ nacionales $^{77}$.

Esta estrategia intelectual encuentra su marco estético-formal y una vía de difusión clave en el género de la crónica, al que se adscribe una parte importante de los textos de estas superficies monumentales, puesto que, como señaló Carl E. Schorske:

The feuilletonist tended to transform objective analysis of the world into subjective cultivation of personal feelings. He conceived of the world as a random succession of stimuli to the sensibilities, not as a scene of action. The feuilletonist exemplified the cultural type to whom he addressed his columns: his characteristics were narcissism and introversion, passive receptivity toward outer reality, and above all, sensitivity to psychic states. This bourgeois culture of feeling conditioned the mentality of its intellectuals and artists, refined their sensibilities, and created their problems ${ }^{78}$.

Se realiza a través de estos textos un doble trabajo; primero, el que podríamos considerar específico de los procesos de nacionalización, la constitución de una idea de nación, como hemos visto vinculada a unos valores sociales históricos concretos; pero al mismo tiempo se crea una identidad social definida a través de una jerarquía cultural, tanto en el orden material como, fundamentalmente, en el espiritual. Se produce así un enclasamiento de la identidad nacional, en relación a un sistema de valores, pero también a una posición en el campo cultural ${ }^{79}$. Los lectores de clase media, que difícilmente podían sentirse socialmente herederos de esa cultura hidalga, nobiliaria e historicista, por la doble vía del conocimiento histórico y la sensibilidad espiritual, es decir, poniendo en juego unos capitales culturales específicos, se

77 BOURDIEU, 1999: 72 y ss.

78 SCHORSKE, 1981: 9. Folletinista es usado en su sentido alemán de cronista cultural en la prensa.

79 BOURDIEU, 2000b: 53-54, 72-73. 
constituyen frente a esos textos como sujetos constituidos por una identidad al mismo tiempo nacional y social, obteniendo como resultado un ennoblecimiento simbólico distintivo. Una vez que esos valores nacionales en principio culturales pasan a formar parte de la propia identidad distintiva como clase social, se abrirían las posibilidades de movilizar políticamente a estas clases medias, a través de una homología entre la posición en el espacio cultural, social y político ${ }^{80}$.

La defensa de esa posición distintiva, capaz de sentir lo nacional, es tematizada constantemente en los textos sobre monumentos en la apelación al privilegio de poseer sensibilidad frente a esas «piedras históricas», acusando al mismo tiempo de mal gusto y filisteísmo a aquellos que no eran capaces de valorarlas ${ }^{81}$. Y junto al «sentimentalismo estético» que estos espacios proporcionan como «impresiones de arte» ${ }^{82}$, hay una marcada conciencia del valor de la historia, parte, como veíamos, del capital cultural de esas clases medias.

Esta contemplación estética no está exenta al mismo tiempo de valores morales o prepolíticos en sí misma. Así, para Ángel Dotor, frente a las tensiones de la vida moderna, su aceleración y frivolidad encarnadas en la vida urbana,

son estos viejos lugares castellanos cual relicarios siempre abiertos al recuerdo del pretérito esplendor de la raza. Los monumentos vetustos que se conservan, como el carácter de la masa de su población, que en ellos perdura con las recias virtudes ancestrales, constituyen perenne manantial en el que debían saciar su sed de ideal todos los amantes de la belleza y del ensueño ${ }^{83}$.

De nuevo, la experiencia de estos espacios del intelectual, verdadera «fiesta para espíritu» — «a nosotros, que hemos sido visitantes de su recinto, nos cautiva el prístino sentido de tradición caballeresca, de leyenda poética que despiertan sus piedras milenarias»-, se convierte en el modelo de sensibilidad para los lectores, a los que simultáneamente se les demanda reconocerse en esos valores espirituales verdaderos, frente a la falsedad de la vida mundana $^{84}$. De algún modo se espera que esta contemplación de los espacios mo-

80 Véase como ejemplo de uso político de esta cultura de hidalguía la movilización contra el catalanismo de la Asociación Nacional de Mujeres Españolas en diciembre de 1918, estudiada por MORENO LUZÓN, 63 (Madrid, 2006): 130-131.

81 ANÓNIMO, 612 (Madrid, 1925). Sobre el mal gusto, aplicado en concreto a los reformistas urbanos ver TORRES BALBÁS, 488 (Madrid, 1923) y SÁNCHEZ ROJAS, 842 (Madrid, 1930).

82 LAMPÉREZ Y ROMEA, 1.447 (Madrid, 1919); 1.462 (Madrid, 1919); 1.478 (Madrid, 19191). LAGO, 760 (Madrid, 1928).

83 DOTOR, 610 (Madrid, 1925).

84 MONTERO ALONSO, 565 (Madrid, 1924) iguala explícitamente a artistas y observadores sensibles en general: 
numentales, tanto a través de la imagen reproducida como de la presencia directa, tenga un efecto de construcción del espíritu nacional ${ }^{85}$. En alguna ocasión esos valores morales se expresan de manera aún más explícita, como en el caso de L. Alonso, que une a ese contraste entre el mundo moderno y los valores nacionales un marcado mesianismo político:

¡Castillo de San Servando, castillo de Poesía y de Leyenda! Sobre tus muros derruidos surgirán pronto las vulgares paredes de una fábrica, y en ella, los ruidos de las modernas máquinas se mezclarán con el sordo rumor de la enconada lucha que han entablado el Trabajo y el Capital — Ambición y Codicia-. Más no importa. Con tus viejas piedras irán cayendo estos nuevos groseros ideales del becerro de oro, que no sacian el alma, y entonces al rumor de las máquinas ultramodernas se mezclarán los versos del rudo poema del héroe castellano, los dulces ecos de la bella leyenda de aquella Reina que defendió Toledo con su ingenio y belleza ${ }^{86}$.

Pero pese a estos usos prepolíticos concretos, dirigidos a la movilización a través de esos valores espirituales establecidos por los intelectuales, las superficies monumentales convierten al lector, fundamentalmente, primero a través de la página y luego en la realidad, en un «turista espiritual», distinto al turista vulgar del Baedecker, en un verdadero «evocador español» ${ }^{87}$.

\section{CONSUMIR LA NACIÓN: LA PRENSA GRÁFICA Y EL TURISMO DE IDENTIDAD CULTURAL}

En efecto, no conviene ser demasiado idealista sobre el valor final de todo este discurso nacionalizador dirigido a las clases medias. Pronto se hace evidente que, si por un lado los lectores son interpelados como sujetos sensibles, capaces de sentir los valores nacionales encarnados en esos espacios, difundi-

Poetas, novelistas, pintores, cantaron en páginas y lienzos la belleza inmortal de la ciudad, con sus callejuelas retorcidas, su catedral gloriosa, sus templos admirables, sus crepúsculos melancólicos, sus murallas seculares, sus piedras varias veces centenarias.... Y la ciudad de Santa Teresa seguirá siendo tema inagotable de arte para todo el que siente encendido su espíritu en los fervores de la Tradición y de la Belleza.

85 Para AMECÉ, 1.425 (Madrid, 1918), el visitante del santuario de Covadonga habrá «dado por bien empleada la caminata, seducida tu vista por la magnificencia del panorama, halagado tu oído por la leyenda y la tradición y fortalecido tu espíritu por el recuerdo de una de las glorias más grandes de España».

86 ALONSO, 430 (Madrid, 1922), que concluye «Castilla volverá a levantar sus castillos de ideales. Por sus campos cabalgará un nuevo Díaz de Vivar, que irá a la reconquista de aquellos sus solares, o donde aún resuenan los ecos de la Leyenda y la Poesía. Con él irán muchos».

87 ANÓNIMO, 845 (Madrid, 1930). BELLO, 767 (Madrid, 1928). El término «evocador español» en GÓMEZ DE LA SERNA, 449 (Madrid, 1922). 
dos a través de las superficies monumentales, en realidad se les está considerando potenciales consumidores de la nación antes que otra cosa. En primer lugar, y de manera evidente, como compradores y lectores de estas revistas, que hacían de lo nacional uno de los elementos fundamentales de sus contenidos, pero también como potenciales consumidores de esos lugares y experiencias en vivo a través del turismo. La nación se convierte así tanto en una experiencia espiritual para el ciudadano sensible como en una mercancía explotable, generadora de riqueza. La prensa gráfica nos recuerda de este modo que no podemos estudiar el valor simbólico de la nación sin restituirlo a su realidad de mercancía en circulación en un mercado cultural que se convierte así en instancia de nacionalización, con frecuencia más eficaz que el propio Estado ${ }^{88}$.

Este proceso de mercantilización de la nación se articuló fundamentalmente a través de productos específicos como la prensa gráfica, el libro de arte, los muebles o los espectáculos teatrales, pero también del consumo del propio espacio nacional con el turismo, que se trató de dinamizar a través de este imaginario geográfico de lo histórico y monumental ${ }^{89}$. Como ha señalado Juan Carlos Ara Torralba, los textos modernistas sobre las almas regionales y las visitas a pequeñas ciudades pintorescas - Santillana del Mar, Toledoprobablemente habían contribuido ya a promocionar el sector turístico a principios de siglo, pero el proceso aún se iría haciendo más evidente a partir del $\mathrm{V}$ Congreso Internacional de Turismo, celebrado en Madrid en octubre de 1912, en cuya cuarta sección, dedicada a la arquitectura, se discutió sobre el valor turístico de las ciudades artísticas y monumentales y se propuso la creación de guías monumentales de todas las provincias españolas ${ }^{90}$. No mucho después, en 1913, la revista Cultura Hispano-Americana editaba un especial Pro Patria, en el que Blanca de los Ríos y su marido Vicente Lampérez pretendían ampliar ese mercado turístico llamando a todos los hispanoamericanos a viajar a España para descubrir las esencias de la Hispanidad, encarnadas en lo que denominaban «santuarios históricos de la raza». Entre ellos se contaban Numancia, Covadonga, el árbol de Guernica, La Rábida, Palos de la Frontera, el Madrid del «Dos de Mayo», Bailén, Zaragoza, Gerona y Cádiz, lugares todos ellos cantados por el poeta nacionalista Marciano Zurita años más tarde en su serie monumental «Del Noble Solar Hispano», publicada en Blanco y Negro en $1918^{91}$. La relación entre turismo identitario y lugares históricos resultaba ya entonces completamente evidente. Luis Antón del Olmet

88 Sobre la nación como objeto de consumo ver THIESSE, 2001: 255-259.

89 Sobre turismo ver MENÉNDEZ ROBLES, 2006. La relación entre turismo, nacionalismo y otro medio de masas como es el cine ha sido explorada en REY REGUILLO, 2007; 69 (Valencia, 2012).

90 ARA TORRALBA 1996: 144-145. V CONGRESO INTERNACIONAL DE TURISMO, 1913: 127 y ss.

91 PRO PATRIA, 1913: 25-48. HERNÁNDEZ CANO, 2009. 
insistió en el almanaque de Blanco y Negro para 1917 en que durante el mes de julio se practicase un «Veraneo españolista» viajando por la península. J. Loygorri ilustraba el artículo, como no podía ser menos, con modernas figuras de turistas que acudían en coche a visitar y fotografiar las catedrales españolas ${ }^{92}$. Incluso no fue infrecuente que el Estado mismo participase con doble intención turística y nacionalista en la revitalización de lugares históricos, como sucedió por esos años con el monasterio de Covadonga ${ }^{93}$.

Durante los años veinte, el público al que muchos de estos textos difundidos por la prensa gráfica se dirigían era el turista, al que se le ofrecían constantemente nuevos itinerarios ${ }^{94}$. Como bien mostraba, por ejemplo, Ángel Dotor, todo lo que hemos visto hasta ahora - monumentos, espíritu nacional, emociones, historia, etc.- - se unía en un sólo producto, como sucedía en Segovia, que ofrecía «la evocación de todo el sentido de la compleja formación de nuestra estirpe: pasadas contiendas, cultura secular, fe y religiosidad ancestrales, agrarismo....», y que estaba fundamentalmente dirigido a esos «evocadores españoles» que eran los turistas nacionales ${ }^{95}$. Pero el potencial mercantil del turismo hacía que, como era de esperar, este discurso buscase también el turismo internacional incluso en el momento en el que la guerra mundial lo hacia imposible, pero que se revitalizó poco después, alcanzando mayor importancia, según algunos autores, que el turismo nacional, lo que fue motivo de preocupación frecuente ${ }^{96}$. Progresivamente, las actividades del Patronato Nacional de Turismo, el desarrollo urbano y la mejora de las redes de comunicación, unida a la proliferación de automóviles privados, hicieron que el turismo nacional creciese, de tal modo que a principios de los años treinta el discurso puramente turístico había acabado por borrar casi por completo de estas superficies monumentales el discurso nacionalista que las había movido durante la década anterior $^{97}$. El lenguaje sobre las ciudades y monumentos continuaba siendo el mismo que durante los años veinte, pero el objeto era ahora claramente cultural y económico, como mostró el especial que La Esfera dedicó en su número del 18 de octubre de 1930 al otoño, claramente destinado a la promoción del turismo. El número se abría con una imagen de «Toledo, como un símbolo en el panorama español...», que,

92 ANTÓN DEL OLMET, 1.337 (Madrid, 1917).

93 BOYD, 2007: 283-284.

94 SARTHOU, 1.399 (Madrid, 1918). ANÓNIMO, 810 (1929) muestra cómo el interés en la ciudad de Sigüenza fue revitalizado por la inclusión en la plaza mayor de El Poble Espanyol de la Exposición Universal de Barcelona de una reproducción del Ayuntamiento de la ciudad.

95 DOTOR, 613 (Madrid, 1925).

96 FRANCÉS, 758 (Madrid, 1928).

97 PITA, 1.477 (Madrid, 1919). TORMES, 595 (Madrid, 1925). HERRERA, 872 (Madrid, 1930). FERRAGUT, 876 (Madrid, 1930). ROMÁN MARTÍNEZ, 544 (Madrid, 1924). 
con la misma arrogancia con que alza sus muros imperiales el paisaje austero de Castilla, destaca su prestigio en el panorama turístico español... Estación forzosa de las rutas de todas las nobles curiosidades intelectuales; joya, archivo, relicario y monumento a la vez, Toledo resume y simboliza las más puras glorias del Arte y de la Historia de nuestra raza.

Claramente el prestigio histórico y la sentimentalización eran ahora motivo explícito para el turismo, más que la formación de un espíritu nacional. Unas páginas más adelante se alababa la labor realizada por el Patronato Nacional del Turismo para dinamizar un sector fundamental para la riqueza nacional en un momento en que los medios de comunicación son más baratos y cómodos, y la queja jeremiaca por el abandono de los monumentos históricos se sustituía ahora por una llamada al Estado para que dirigiese la organización del turismo nacional ${ }^{98}$. Las glorias de la historia española, carne del espíritu mismo de la nación ante el que sólo las sensibilidades escogidas se sentían conmovidas, materializado en esos monumentos cuya imagen había fatigado las páginas de la prensa gráfica durante décadas, acababan así convertidas en una atracción turística dirigida al extenso mercado de la identidad nacional.

\section{CONCLUSIÓN: REPENSAR EL NACIONALISMO CULTURAL}

Lo que he pretendido en las páginas precedentes ha sido sugerir algunos de los complejos significados políticos, sociales y culturales que se pueden encontrar en un gesto aparentemente tan sencillo como apenas ojear una revista, leyendo algunos artículos o poemas, en un momento histórico concreto. A través de este elemento en apariencia menor de nuestra historia cultural he podido trazar un primer acercamiento al fundamental papel de la producción y el consumo culturales en la construcción del nacionalismo español contemporáneo. Muchos otros restos materiales de nuestro pasado, despreciados por su mediocridad, por su superficialidad, esperan esparcidos en impresos y objetos diversos a que les restituyamos su valor y funciones para una comprensión cabal de la cultura nacionalista española de los pasados siglos. Creo que su recuperación sería necesaria para repensar la jerarquía de los símbolos de la cultura nacional y su papel en la nacionalización, relativizando el valor del binomio Estado / intelectuales frente a un mercado estructurado de manera compleja en diversos niveles socioculturales de consumo, que en algunos casos se aproximaban, con los matices que hemos establecido en el texto, a una naciente cultura de masas.

Al mismo tiempo, el estudio de los valores vinculados a los monumentos históricos nos permite comprobar el desplazamiento de la esencia nacional a

98 GAY DE OCHOA, 876 (Madrid, 1930). 
objetos y espacios que incorporan el pasado histórico. Las estrategias específicas de producción y consumo que propiciaban los medios que, como la prensa gráfica, difundían ese discurso sobre lo monumental, como he tratado de teorizar, pudieron influir de manera determinante en la definición de una idea de nación con una clara marca social, en absoluto inclusiva. He tratado de sugerir con ello que tal vez aquellas prácticas que podemos identificar como constructoras de la identidad nacional no solamente nacionalizaban, sino que tuvieron un papel más complejo en la configuración de identidades y prácticas sociales en la España del primer tercio del siglo veinte.

\section{BIBLIOGRAFÍA}

Alejandro, Luis, «Postales de Tenerife. La Laguna, ciudad castellana», Nuevo Mundo, 1.886 (Madrid, 1930).

Alonso, Cecilio, «La formación de la conciencia nacional en las primeras revistas ilustradas españolas (1836-1854)», en Alberto Gil Novales (ed.), La Revolución liberal. Congreso sobre la Revolución liberal española en su diversidad peninsular (e insular) y americana, Madrid, abril de 1999, Madrid, Ediciones del Orto, 2001; 611-633.

Alonso, Cecilio, Historia de la Literatura Española 5. Hacia una literatura nacional. 1808-1898, Barcelona, Crítica, 2010.

Alonso, L., «Piedras viejas. El castillo de San Servando», La Esfera, 430 (Madrid, 1922).

Álvarez Junco, José, Mater Dolorosa. La idea de España en el siglo XIX, Madrid, Taurus, 2001.

Álvarez Junco, José, «Prólogo», en Josep María Fradera, Cultura nacional en una sociedad dividida. Cataluña, 1838-1868, Madrid, Marcial Pons, 2003.

Amecé [Ángel María Castell], «Las fiestas del centenario. Covadonga», Blanco y Negro, 1425 (Madrid, 1918).

Anderson, Benedict, Imagined Communities. Reflections on the Origin and Spread of Nationalism, London / New York, Verso, 1991.

Anónimo, «El arte en el cine. La casa de la Troya», La Esfera, 579 (Madrid, 1925a).

Anónimo, «Las ciudades históricas», La Esfera, 579 (Madrid, 1925b).

Anónimo, «España pintoresca. La villa de Monbeltrán», La Esfera, 579 (Madrid, 1925c).

Anónimo, «Tres relicarios del glorioso arte español. Granada, Córdoba, Toledo, ciudades de emoción y ensueño», La Esfera, 600 (Madrid, 1925).

Anónimo, «Estampas de Villa-Amil. El transparente de la catedral de Toledo», La Esfera, 608 (Madrid, 1925).

Anónimo, «Viejas estampas. La colegiata de Toro», La Esfera, 609 (Madrid, 1925). 
Anónimo, «Estampas de Villa-Amil. El patio del palacio de Alcalá de Henares», La Esfera, 610 (Madrid, 1925).

Anónimo, «Piedras viejas. Rincones de Cáceres», La Esfera, 612 (Madrid, 1925).

Anónimo, «La casa de la Troya en película», Nuevo Mundo, 1. 619 (Madrid, 1925).

Anónimo, «Alcázares de España», La Esfera, 783 (Madrid, 1929).

Anónimo, «Las viejas ciudades de Castilla», La Esfera, 784 (Madrid, 1929): 1.

Anónimo, «Ciudades olvidadas. Sigüenza», La Esfera, 810 (Madrid, 1929: 21-28.

Anónimo, «Evocaciones de un pasado glorioso. Un escenario apacible de muchas escenas trágicas», La Esfera, 845 (Madrid, 1930): 21-23.

Antón del Olmet, Luis, «Veraneo españolista», Blanco y Negro, 1.337 (Madrid, 1917).

Ara Torralba, Juan Carlos, Del modernismo castizo. Fama y alcance de Ricardo León, Zaragoza, Prensas Universitarias de Zaragoza, 1996.

Ariño Colás, José María, Recuerdos y Bellezas de España: Ideología y estética. Zaragoza, CSIC, 2007.

Bello, Luis, «Madrid y su prensa gráfica», La Esfera, 1 (Madrid, 1914).

Bello, Luis, «Ante las piedras de Segovia. Lo genuino y lo extranjero», La Esfera, 537 (Madrid, 1924).

Bello, Luis, «Ciudades del Renacimiento. Los tesoros de Úbeda», La Esfera, 767 (Madrid, 1928): 34-35.

Benítez, Rubén, Bécquer tradicionalista, Madrid, Gredos, 1971.

Benjamin, Walter, «The Work of Art in the Age of Mechanical Reproduction», Illuminations. Essays and Reflections, New York, Schocken Books, 2007; 217-251.

Berthier, Nancy y Jean-Claude Seguin (dir.), Cine, nación y nacionalidades en España, Madrid, Casa de Velázquez, 2007.

Billig, Michael, Banal Nationalism, London, Sage, 1995.

Bourdieu, Pierre, Meditaciones pascalianas, Barcelona, Anagrama, 1999.

Bourdieu, Pierre, Cosas dichas, Barcelona, Gedisa, 2000a.

Bourdieu, Pierre, Cuestiones de sociología, Madrid, Istmo, $2000 \mathrm{~b}$.

Bourdieu, Pierre, «Las formas del capital. Capital económico, capital cultural y capital social», Poder, derecho y clases sociales, Bilbao, Desclée de Brouwer, 2001; 131-164.

Boyd, Carolyn P., Historia Patria: Politics, History, and National Identity in Spain, 1875-1975, Princeton, Princeton University Press, 1997.

Boyd, Carolyn P., «Paisajes míticos y la construcción de las identidades regionales y nacionales: el caso del santuario de Covadonga», en Carolyn P. Boyd (ed.), Religión y política en la España contemporánea, Madrid, Centro de Estudios Políticos y Constitucionales, 2007; 271-294.

Buck-Morss, Susan, The Dialectics of Seeing. Walter Benjamin and The Arcades Project, Cambridge / London, The MIT Press, 1995. 
Bussy Genevois, Danièle (dir.), Le projet national de «Blanco y Negro» (18911917), Saint-Denis, Université Paris 8 Vincennes-Saint-Denis, 1991.

Cabrera, Mercedes, La industria, la prensa y la política. Nicolás M. ${ }^{a}$ de Urgoiti, Madrid, Alianza Editorial, 1994.

Castell, Ángel María, «Ciudades española. Burgos», Blanco y Negro, 1.463 (Madrid, 1919).

Castro, Cristóbal de, «En la fiesta de la raza. La raza ante la evocación y la raza ante la profecía», La Esfera, 876 (Madrid, 1930): 20.

Cavestany, J. A., «En Santiago de Compostela», Blanco y Negro, 1413 (Madrid, 1918).

Charnon-Deutsch, Lou, «From Engraving to Photo: Cross-cut Technologies in the Spanish Illustrated Press», Hold That Pose. Visual Culture in the Late NineteenthCentury Spanish Periodical, University Park, Pennsylvania State University Press, 2008; 45-82.

Cirujano Marín, Paloma, Teresa Elorriaga Planes y Juan Sisinio Pérez Garzón, Historiografía y nacionalismo español (1834-1868), Madrid, Centro de Estudios Históricos, 1985.

Contreras y Camargo, E., «Pueblos fronterizos. Ciudad Rodrigo, La heroica», La Esfera, 768 (Madrid, 1928): 10-11.

D. T. , «El poder de la poesía. Una ciudad dos veces milenaria», La Esfera, 761 (Madrid, 1928).

Derrida, Jacques, Spectres of Marx. The State of the Debt, the Work of Mourning and the New International, New York and London, Routledge, 2006.

Dotor, Ángel, «Solares de la raza. La antiquísima villa de Coca y su maravilloso castillo mudéjar», La Esfera, 591 (Madrid, 1925).

Dotor, Ángel, «Los antiguos señoríos españoles. Cuellar. El del ensueño y la leyenda», La Esfera, 610 (Madrid, 1925).

Dotor, Ángel, «Las ciudades españolas. Visión de Segovia», La Esfera, 613 (Madrid, 1925).

Dotor, Ángel, «Mirando a Castilla. La histórica y pintoresca Sepúlveda», La Esfera, 743 (Madrid, 1928): 16-17.

Fernández Sebastián, Javier y Juan Francisco Fuentes (eds.), Diccionario político y social del siglo XIX español, Madrid, Alianza Editorial, 2002.

Ferragut, Juan, «Rutas de turismo que hay que prestigiar. De Cádiz, la señorita, a Sevilla, la reina...», La Esfera, 876 (Madrid, 1930): 8.

Flitter, Derek, Spanish Romanticism and the Uses of history. Ideology and the Historical Imagination, London, Modern Humanities Research Association and Maney Publishing, 2006.

Fox, Inman, La invención de España. Nacionalismo liberal e identidad nacional, Madrid, Cátedra, 1998.

Francés, José, «Un libro de exaltación española. 'La bendita tierra'», La Esfera, 758, (Madrid, 1928): 9. 
Francés, José, «Escolios artísticos. Nueva mirada a Santillana del Mar», La Esfera, 807 (Madrid, 1929): 6-7.

Fritzsche, Peter, Stranded in the Present. Modern Time and the Melancholy of History, Cambridge / London, Harvard University Press, 2004.

Fusi, Juan Pablo, España. La evolución de la identidad nacional, Madrid, Temas de hoy, 2000.

García Carrión, Marta, Sin cinematografía no hay nación: drama e identidad nacional española en la obra de Florián Rey, Zaragoza, CSIC, 2007.

García Carrión, Marta, «Escribir sobre cine para hablar de España: Discursos de nacionalismo español en la cultura cinematográfica de los años veinte y treinta», en Ismael Saz y Ferran Archilés (coords.), Estudios sobre nacionalismo y nación en la España contemporánea, Valencia, Publicacions de la Universitat de València, 2011; 169-202.

García Carrión, Marta, Por un cine patrio. Cultura cinematográfica y nacionalismo español (1926-1936), Valencia, Universitat de València, 2013.

García Melero, José Enrique, Literatura española sobre artes plásticas. Volumen 2 Bibliografía aparecida en España durante el siglo XIX, Madrid, Ediciones Encuentro, 2002.

García Sainz de Baranda, Julián, «Por tierras de Castilla-Vieja. Castillos, palacios y casonas», La Esfera, 814 (Madrid, 1929): 39-40.

Gay de Ochoa, Rafael, «La obra verdaderamente patriótica del Patronato Nacional del Turismo», La Esfera, 876 (Madrid, 1930): 7.

Gómez de la Serna, Ramón, «Segovia la abandonada», La Esfera, 449 (Madrid, 1922).

Guerra, Ángel, «Ciudades de España. Santa Cruz de Tenerife», Blanco y Negro, 1490 (Madrid, 1919).

Gumbrecht, Hans Ulrich, Production of Presence. What Meaning Cannot Convey, Stanford, Stanford University Press, 2004.

Hernández Cano, Eduardo, «Modernismo nacionalista y prensa gráfica. Marciano Zurita en Blanco y Negro (1918-1919)», en Javier Serrano Alonso y Amparo de Juan Bolufer (coord.), Literatura hispánica y prensa periódica (1875-1931): Actas del congreso internacional, Lugo, 25-28 de noviembre de 2008, Santiago de Compostela, Universidade de Santiago de Compostela / Servizo de Publicacións e Intercambio Científico, 2009; 381-402.

Herrera, Santiago, «Un problema de urbanismo. Ciudades viejas que quieren remozarse», La Esfera, 872 (Madrid, 1930): 38-42.

Hinterhäuser, Hans, «Ciudades muertas», Fin de siglo. Figuras y mitos, Madrid, Taurus, 1998; 41-66.

Holguín, Sandie, Creating Spaniards. Culture and National Identity in Republican Spain, Madison, University of Wisconsin Press, 2002.

Hoyos, Julio, «De las ciudades castellanas. La sombra de la catedral», La Esfera, 473 (Madrid, 1923). 
Iglesias, Francisco, Historia de una empresa periodística. Prensa Española. Editora de «ABC»y «Blanco y Negro» (1891-1978), Madrid, Editorial Prensa Española, 1978.

Jover, José María, La civilización española a mediados del s. XIX, Madrid, Espasa Calpe, 1991.

Juliá, Santos, Historias de las dos Españas, Madrid, Taurus, 2004.

Kracauer, Siegfried, «The Mass Ornament», The Mass Ornament. Weimar Essays, Cambridge / London, Harvard University Press, 1995; 75-86.

La prensa ilustrada en España. Las Ilustraciones, 1850-1920, Montpellier, Iris Université Paul Valéry, 1996.

Labanyi, Jo, «Horror, Spectacle and Nation-formation: Historical Painting in the Late-nineteenth-century Spain», en Susan Larson y Eva Woods (eds.), Visualizing Spanish modernity, Oxford / New York, Berg, 2005; 64-80.

Lago, Silvio [José Francés], «Una obra de arte. Estampas compostelanas», La Esfera, 760 (Madrid, 1928): 11-15.

Lago, Silvio [José Francés], «El poder emotivo de la fotografía», Nuevo Mundo, 1.841 (Madrid, 1929).

Lampérez y Romea, Vicente, «Las catedrales españolas. II Las de Salamanca», Blanco y Negro, 1.447 (Madrid, 1919).

Lampérez y Romea, Vicente, «Las catedrales españolas. III. La de Ávila», Blanco y Negro, 1.455, (Madrid, 1919).

Lampérez y Romea, Vicente, «La Catedral de Cuenca. IV», Blanco y Negro, 1462, (Madrid, 1919).

Lampérez y Romea, Vicente, «La catedral de León. VI», Blanco y Negro, 1478 (Madrid, 1919).

Lampérez y Romea, Vicente, «La catedral de Toledo. VII», Blanco y Negro, 1.483 (Madrid, 1919).

López Martín, Fernando, «Blasones», La Esfera, 851 (Madrid, 1930): 30.

López Martín, Fernando, «Piedras», La Esfera, 669 (Madrid, 1926): 32.

López Núñez, Juan, «Las viejas ciudades y el alma del pasado», Nuevo Mundo, 1.710 (Madrid, 1926).

Lozano, Luis, «De la España artística. Sigüenza, la ciudad del doncel», La Esfera, 753, (Madrid, 1928): 19.

Maestre Abad, Vicente, «Recuerdos y bellezas de España. Su origen ideológico, sus modelos», Goya. Revista de Arte, 181-182 (Madrid, 1984): 86-93.

Mainer, José-Carlos, Historia de la literatura española 6. Modernidad y nacionalismo (1900-1939), Barcelona, Crítica, 2010.

Marcilhacy, David, Raza hispana. Hispanoamericanismo e imaginario nacional en la España de la Restauración, Madrid, Centro de Estudios Políticos y Constitucionales, 2010. 
Mendelson, Jordana, Documenting Spain: Artists, Exhibition Culture, and the Modern Nation, 1929-1939, Pennsylvania Park, Pennsylvania State University Press, 2005. [Trad. en Documentar España. Los artistas, la cultura expositiva y la nación moderna, 1929-1939, Barcelona, Ediciones de La Central / Museo Nacional Centro de Arte Reina Sofía, 2012.]

Menéndez Robles, María Luisa, El Marqués de la Vega Inclán y los orígenes del turismo en España, Madrid, Secretaría General de Turismo, 2006.

Mesonero Romanos, Ramón de, Memorias de un setentón, natural y vecino de Madrid, Tomo segundo (1824-1850), Madrid, Oficinas de la Ilustración Española y Americana, 1881.

Meseguer, Manuel Nicolás, La intervención velada. El apoyo cinematográfico alemán al bando franquista (1936-1939), Murcia, Universidad de Murcia / Primavera Cinematográfica de Lorca, 2004.

Ministerio de Instrucción Pública y Bellas Artes. Dirección general del Instituto Geográfico y Estadístico, Estadística de la prensa periódica de España (Referida al $1^{\circ}$ de febrero del año 1920), Madrid, Talleres del Instituto Geográfico y Estadístico, 1921.

Ministerio de Trabajo y Previsión. Servicio General de Estadística, Estadística de la prensa periódica de España (Referida al 31 de diciembre del año 1927), Madrid, Imprenta de los Hijos de M. G. Hernández, 1930.

Montero Alonso, José «Caminos de la montaña... Santillana la muerta», La Esfera, 446 (Madrid, 1922).

$\mathrm{M}$ [ontero] A[lonso], J[osé], «Los relicarios de la raza. Medina del Campo y su castillo de la Mota», La Esfera, 562 (Madrid, 1924).

M[ontero] A[lonso], J[ose], «La Iglesia románica de San Segundo en Ávila», La Esfera, 565 (Madrid, 1924).

Montero Alonso, José, «Caminos de la Montaña. Santillana, la villa silenciosa y prócer», La Esfera, 606 (Madrid, 1925).

Montero Alonso, José, «Rutas de España. Sonata de otoño en León», La Esfera, 623 (Madrid, 1925).

Morales Moya, Antonio y Mariano Esteban de Vega (eds.), ¿Alma de España? Castilla en las interpretaciones del pasado español, Madrid, Marcial Pons, 2005.

Morand, Paul, Feuilles de température, París, Au Sans Pareil, 1920.

Moreno Alonso, Manuel, Historiografía romántica española. Introducción al estudio de la historia en el siglo XIX, Sevilla, Universidad, Servicio de Publicaciones, 1979.

Moreno Luzón, Javier, «De agravios, pactos y símbolos: el nacionalismo español ante la autonomía de Cataluña», Ayer, 63 (Madrid, 2006): 119-131.

Moreno Luzón, Javier, (ed.), Construir España. Nacionalismo español y procesos de nacionalización, Madrid, Centro de Estudios Políticos y constitucionales, 2007. 
Moreno Luzón, Javier, «Mitos de la España inmortal. Conmemoraciones y nacionalismo español en el siglo XX», en C. Forcadell, I. Saz, P. Salomón, (eds.), Discursos de España en el siglo $X X$, Valencia, Publicacions de la Universitat de València, 2009; 123-146.

Mosse, George L., La nacionalización de las masas. Simbolismo político y movimientos de masas en Alemania desde las Guerras Napoleónicas al Tercer Reich, Madrid, Marcial Pons, 2005.

Muro, Diego y Alejandro Quiroga, «Spanish Nationalism. Ethnic or Civic?» Ethnicities, 5/1 (Londres, 2005): 9-29.

Nora, Pierre (dir.), Les Lieux de Mémoire, 3 vols., Paris, Gallimard, 1997.

Olmedilla, Juan G., «Vieja España. Trujillo, tierra de conquistadores», La Esfera, 816 (Madrid, 1929): 32-33.

Peiró Martín, Ignacio, Los guardianes de la historia. La historiografía académica de la Restauración, Zaragoza, CSIC, 2006.

Pellistrandi, Benoît, Un discours national? La Real Academia de la Historia entre science et politique (1847-1897), Madrid, Casa de Velázquez, 2004.

Pita, Federico, «Rincones de España. Páginas Gallegas. Betanzos», Blanco y Negro, 1.452 (Madrid, 1919).

Pita, Federico, «Ciudades de España. Orense», Blanco y Negro, 1.465 (Madrid, 1919).

Pita, Federico, «Capitales españolas. Lugo», Blanco y Negro, 1.473 (Madrid, 1919).

Pita, Federico, «Capitales españolas. La Coruña», Blanco y Negro, 1.477 (Madrid, 1919).

Pita, Federico, «Capitales de España. Toledo», Blanco y Negro, 1.485 (Madrid, 1919).

Pro Patria. Número extraordinario de la revista Cultura Hispano-Americana, dedicado al turismo, Madrid, Est. Tip. de El Liberal, 1913.

Quiroga, Alejandro, Making Spaniards. Primo de Rivera and the Nationalization of the Masses, 1923-1930, London, Palgrave Macmillan, 2007.

Ramírez Ángel, E., «Rincones españoles. La villa de Santillana del Mar», La Esfera, 559 (Madrid, 1924)

Rey Reguillo, Antonia del (ed.), Cine, imaginario y turismo. Estrategias de seducción, Valencia, Tirant lo Blanch, 2007.

Rey Reguillo, Antonia del (coord.), «Cine y turismo: intersecciones polivalentes», Archivos de la Filmoteca, 69 (Valencia, 2012).

Román Martínez, Pedro, «Ciudades españolas. Alcaraz», La Esfera, 544 (Madrid, 1924).

Roth, Joseph, Crónicas berlinesas, Madrid, Editorial Minúscula, 2006.

Rubio Jiménez, Jesús, «Modernismo y teatro poético (1900-1914): una revisión necesaria», El teatro poético en España: del modernismo a las vanguardias, Murcia, Secretariado de Publicaciones y Servicio de Actividades culturales de la universidad de Murcia, 1993; 11-51.

Runia, Eelco, «Spots of Time», History and Theory, 45 (Middletown, 2006): 305-316. 
Salaün, Serge, «La zarzuela finisecular o el consenso nacional», en L. García (ed.), Ramos Carrión y la zarzuela: actas de las jornadas sobre Ramos Carrión y la zarzuela celebradas en Zamora en noviembre de 1988, Zamora, Instituto de Estudios Zamoranos Florián de Ocampo, 1993; 11-23.

Salaün, Serge, «Zarzuela e historia nacional (Cádiz y La Marsellesa)», en Jacqueline Covo (ed.), Las representaciones del tiempo histórico, Lille, Presses Universitaires de Lille, 1994; 179-186.

Sánchez Illán, Juan Carlos, La nación inacabada. Los intelectuales y el proceso de construcción nacional (1900-1914), Madrid, Biblioteca Nueva, 2002.

Sánchez Rojas, José, «Ciudades viejas de España. Oviedo», La Esfera, 4 (Madrid, 1914).

Sánchez Rojas, José, «Ciudades españolas. Cáceres», La Esfera, 766 (Madrid, 1928): 38.

Sánchez Rojas, José, «Sensaciones de las viejas ciudades de Castilla. Zamora, la ciudad del romancero», Nuevo Mundo, 1.792, (Madrid, 1928).

Sánchez Rojas, José, «Sevilla. Meditación en la ciudad», Nuevo Mundo, 1.833 (Madrid, 1929).

Sánchez Rojas, José, «El tesoro artístico nacional. El coro de la catedral de Barcelona», La Esfera, 842, (Madrid, 1930): 5.

Sánchez Rojas, José, «Villas castellanas. Alba de Tormes», La Esfera, 845 (Madrid, 1930): 12-13.

Sánchez Vigil, Juan Miguel, Revistas ilustradas en España. Del Romanticismo a la guerra civil, Gijón, Trea, 2008.

Sarthou, Carlos, «Las ruinas de Poblet», Blanco y Negro, 1.399 (Madrid, 1918).

Sarthou Carreres, Carlos, «Ciudades españolas. La inmortal Sagunto», Blanco y Negro, 1.471 (Madrid, 1919).

Sarthou Carreres, Carlos, «Templos españoles. Vagando ante las puertas de la catedral de Barcelona», La Esfera, 816 (Madrid, 1929): 26-28.

Saz, Ismael y Ferran Archilés (coords.), La nación de los españoles. Discursos y prácticas del nacionalismo español en la época contemporánea, Valencia, Publicacions de la Universitat de València, 2012.

Schorske, Carl E., Fin-de-Siècle Vienna. Politics and Culture, New York, Vintage Books, 1981.

Segalen, Martine, Ritos y rituales contemporáneos, Madrid, Alianza, 2005.

Seoane, María Cruz, Oratoria y periodismo en la España del siglo XIX, Madrid, Castalia / Fundación Juan March, 1977.

Seoane, María Cruz y María Dolores Saiz, Historia del periodismo en España 3. El siglo XX: 1898-1936, Madrid, Alianza Editorial, 1998.

Serrano, Carlos, El nacimiento de Carmen. Símbolos, mitos, nación, Madrid, Taurus, 1999.

Thérenty, Marie-Ève, La littérature au quotidien, Paris, Seuil, 2007. 
Thiesse, Anne Marie, La creation des identities nationals. Europe XVIII ${ }^{e}-X X^{e}$ siècle, Paris, Éditions du Seuil, 2001.

Tormes, A. de, «Viejas estampas. Castillos de España», La Esfera, 595 (Madrid, 1925).

Tormes, A. de, «Viejas estampas. Los dibujos románticos de Villa-Amil», La Esfera, 607 (Madrid, 1925).

Torres Balbás, Leopoldo, «La murallas que caen», La Esfera, 488 (Madrid, 1923).

Valero Martín, Alberto, «La catedral vieja de Salamanca», La Esfera, 629 (Madrid, 1926): 28.

Varela, Javier, La novela de España. Los intelectuales y el problema español, Madrid, Taurus, 1999.

$V$ Congreso Internacional de Turismo de la Federación de los sindicatos de iniciativas franco-hispano-portugués. Memoria general. Madrid, 24 al 30 de Octubre de 1912, Madrid, Artes Gráficas "Mateu”, 1913.

Velasco Zazo, Antonio, «Mirando al pasado. La catedral de Palencia y sus interesantes bellezas», La Esfera, 656 (Madrid, 1926): 30-32.

Wulff Alonso, Fernando, Las esencias patrias. Historiografia e historia antigua en la construcción de la identidad española (siglos XVI-XX), Barcelona, Crítica, 2003.

Zurita, Marciano, «Del Noble Solar Hispano. VII. Ávila», Blanco y Negro, 1.396 (Madrid, 1918).

Zurita, Marciano, «Arcos y puertas. El emblema del triunfo y el símbolo de la defensa», Blanco y Negro, 1.934 (Madrid, 1928).

Recibido: 18-05-2011

Aceptado: 23-05-2012 